Beyond modularisation: The need for a socio-neuro-constructionist model of autism

\author{
Beatriz López \\ Department of Psychology \\ University of Portsmouth \\ King Henry I Building \\ King Henry I Street \\ Portsmouth PO1 2DY \\ United Kingdom
}

Corresponding address: Dr Beatriz López; E-mail: Beatriz.Lopez@port.ac.uk; Tel: +44

(0)2392842016; Fax: +44 (0)2392846300

The final version of this article is published in the Journal of Autism and Developmental Disorders (2015), 45 (1), 31.41.

The DOI for the printed version of this article is: $10.1007 / \mathrm{s} 10803-013-1966-9$ 


\begin{abstract}
Autism is a developmental disorder defined by social and communication impairments. Current theoretical approaches and research studies however conceptualise autism as both static and independent from the social context in which it develops. Two lines of research stand out from this general trend. First, research from the neuroconstructivist approach of Karmiloff-Smith (2010) aims to establish developmental trajectories of cognitive impairments in autism over time. Second, studies from intersubjective approaches such as that of Hobson (2002) focus on the influence of emotional engagement in cognitive impairments. Although these two lines of research have made an invaluable contribution towards our understanding of autism, both offer only partial explanations: Intersubjective approaches fail to provide a developmental perspective and the neuroconstructivist model neglects the role of the social context. This paper argues that the nature of autism demands the theoretical and methodological integration of these two approaches so that developmental and social aspects are investigated in tandem.
\end{abstract}

Keywords: Autism, neuro-contructivism, developmental trajectories, engagement, intersubjectivity

\footnotetext{
Abbreviations: Theory of Mind (ToM), Executive Function (EF), Weak Central Coherence (WCC), Repetitive and Restricted Behaviours (RRBs), Repetitive Sensory Motor Behaviours (RSMBs), Insistence of Sameness (IS),
} 


\section{Beyond modularisation: The need of a socio-neuro-constructionist model of autism}

In recent years important changes have taken place in our understanding of autism. It is now widely recognised that it has a strong genetic component, is characterised by cognitive impairments in Theory of Mind (i.e., social understanding ability; TOM), Executive Function (i.e., flexibility of thought; EF) and Weak Central Coherence (i.e., tendency towards piecemeal processing; WCC) and, behaviourally, by social interaction and communication difficulties, repetitive and restricted behaviours and sensory processing abnormalities (Volkmar, Paul, Klin \& Cohen, 2005). However, although seventy years have passed since Kanner (1943) first described autism, the exact nature of this spectrum of conditions still remains unknown.

As will be argued throughout this article, the failure to develop a full understanding of autism can be partially explained by the continuing lack of information on how autism develops over time and the role of socio-cultural factors in this development. There are two main reasons for this neglect. First, the recognition that autism has a strong genetic component has resulted in an implicit tendency to conceptualise autism as a static condition with symptoms that remain stable across time. For example, the vast majority of researchers in autism favour methodologies in which performance of autistic and non-autistic samples matched for age/ability is compared at a single point in time (see Jarrold \& Brock, 2004 for a review) rather than methodologies that focus on how impairments evolve over time. Similarly, the major current theories of autism such as TOM, EF or WCC explain autism in terms of primary cognitive deficits, believed to have a genetic origin, rather than explanations of developmental interactions between domains of ability/impairment. Yet autism is a developmental disorder and any explanation of autism necessarily has to incorporate a developmental component. 
Second, the dominance of the cognitivist approach to psychology has limited our understanding of how social impairments may play a role in the development of autistic symptoms. Cognitive psychology places little importance on the social context in which a person develops. However, autism is, at its core, a disorder characterised by social impairments and, from its very first description by Kanner (1943), as 'disturbances of affective contact' (p. 250). More importantly, affective engagement and social interactions have been shown to be crucial in the development of symbolic thinking (e.g., Hobson, 2002), language (e.g., Zatlev \& Sinha, 2008), executive functioning (e.g., Lewis \& Carpendale, 2009) and even perception (e.g., Chua, Boland \& Nisbett, 2005). It is therefore quite remarkable that autism keeps being referred to as a combination of social and non-social impairments (e.g. Ronald, Happé \& Plomin, 2005) when the 'non-social' impairments are, at the very least, partially socially constituted. In fact, the dominant theories about autism simply fail to take into account how atypical social interactions influence the development of symptomatology in autism.

Two lines of research stand out from this general tendency to conceptualise autism as both static and independent from the social context in which it develops. First, KarmiloffSmith $(1992 ; 1998 ; 2009$ a) has provided a neuro-constructivist framework which has helped to explain both typical and atypical cognitive development. In particular the work of Karmiloff-Smith and her colleagues has provided extensive evidence that brain specialisation is not innate, but a result of the interaction between the child and the environment, a process she calls modularisation. Evidence for this theoretical framework comes from studies documenting modularisation processes for different cognitive abilities across typical and atypical development (e.g., Karmiloff-Smith et al, 2004; Cornish, Scerif \& Karmiloff-Smith, 2007; Kwon, Reiss \& Menon, 2002). The second line of research, led by Hobson (1993; 2002), Reddy (2009) and others has demonstrated first, that many of the features found in 
autism may be explained as the result of reduced intersubjective engagement (e.g., Reddy, Williams \& Vaughan, 2002) and, second, that the social context, and in particular, intersubjective engagement, influences symbolic development both in typical and atypical development (Hobson et al, 2009).

Although these two lines of research have made an invaluable contribution towards a more comprehensive understanding of autism, both views offer only partial explanations. Karmiloff-Smith's neuroconstructivist model describes how cognitive abilities develop over time in typical and atypical development but fails to explain how modularisation processes in autism may be influenced by impairments in intersubjective engagement. Intersubjective approaches in contrast explain the role of intersubjective engagement in certain autistic symptoms but fail to document the precise developmental trajectory of this relationship. This paper argues that in order to understand autism, and for that matter, typical development, it is necessary to understand the relationship between intersubjectivity and modularisation.

There are numerous examples that illustrate the dangers of not taking into account the influence of social context in modularisation processes. One of the examples most relevant to autism is the development of perceptual biases. There is uncontested evidence that autism is characterised by a local perceptual bias (for a review see Happé \& Frith, 2006) and, this bias, has been assumed to have its origins in organic abnormalities (Spencer et al, 2000; Brock, Brown, Boucher \& Rippon, 2002). However, the development of local and global perceptual biases has been shown to be strongly influenced by social factors. There are cross-cultural differences in the susceptibility to visual illusions (e.g., deFockert et al, 2007), in hierarchical perceptual tasks (Davidoff, Fonteneau \& Fagot, 2008), in change-blindness paradigms (Simons \& Levin, 1997), and in eye-tracking studies (Chua et al, 2005). Crucially, these cultural differences influence modularisation processes: brain activation patterns observed when viewing visual scenes differ across cultures (Gron, Schul, Bretschneider, Wunderlich \& 
Riepe, 2003). Hence, the organic difficulties associated with the presence of a local perceptual bias in autism may be the result of either an innate perceptual abnormality, or, a consequence of innate social difficulties. Investigating which of these alternatives is more likely, is paramount to the development of interventions. In the first case, interventions would aim to compensate for innate perceptual abnormalities. In contrast, the second alternative would require interventions to prevent the difficulty arising in the first place by targeting interventions to enhance whichever social practices result in increased global perceptual bias. As will be argued in detail later, executive function development is also influenced by social factors (e.g., Oh \& Lewis, 2008) and hence may also be subject to preventative rather than compensatory interventions.

Overall, these studies demonstrate that a comprehensive understanding of autism necessitates the integration of 1) knowledge of how it develops over time and 2) knowledge of how social factors influence this development. In other words, the study of autism requires the integration of the neuro-constructive model of Karmiloff-Smith with inter-subjective approaches such as those of Hobson and Reddy rather than treating them as mutually exclusive, or at best, parallel explanations

\section{The importance of taking a developmental approach to the study of autism}

"And, every aspect of development turns out to be dynamic and interactive.

(Karmiloff-Smith, 2009a, p.56)

Karmiloff-Smith's proposal that it is essential to investigate how developmental disorders unfold over time has generated a wealth of evidence relating to the development of cognitive impairments in a wide range of developmental disorders. Karmiloff-Smith's most influential work started as a direct response to Fodor's (1983) suggestion that the brain has 
evolved so that specific areas of the brain (i.e., modules) are responsible for different cognitive functions. In her book 'Beyond modularity' Karmiloff-Smith (1992) proposed instead a neuro-constructivist model of development stating that brain specialisation is not solely determined by genetics but is the result of the interaction between genetic predispositions and the environment. In other words, that modules are the end product of development and not innate as Fodor (1983) had suggested. What she proposes is that we are born with innate attentional pre-dispositions that favour the processing of certain stimuli over others such as, for example, a preference for face-like stimuli (Morton \& Johnson, 1991; Simion, Macchi, Cassia, Turati \& Valenza, 2001). These primitive predispositions, favoured by evolution, ensure that infants attend to environmental stimuli which will enhance their chances of survival. There is now evidence of modularisation processes across a wide range of cognitive functions such as face processing (Johnson \& de Haan, 2001; de Haan \& Nelson, 1999), numeracy (Ansari \& Ditahl, 2006) and visuo-spatial working memory (Kwon, Reiss \& Menon, 2002). At the heart of Karmiloff-Smith's proposal is the idea that, to understand cognition, we cannot simply focus on the end product but need to understand how and when cognitive abilities emerge.

In the same vein, in order to understand atypical development, she argues, we need to understand how impairments develop over time (Karmiloff-Smith, 1998; 2009a; 2009b). Over the last two decades Karmiloff-Smith and other researchers have gathered evidence regarding developmental trajectories of cognitive impairments in different developmental disorders such as motion processing in children with autism (Annaz et al, 2010), hierarchical processing in children with autism and Fragile X (Ballantyne, 2010), face processing in Williams syndrome (Karmiloff-Smith et al, 2004) and attention in Fragile X, Williams syndrome and Down syndrome (Cornish, Scerif \& Karmiloff-Smith, 2007) amongst others. Despite the evidence that impairments in developmental disorders change with age, the large 
majority of research into developmental disorders still favours methodologies in which performance of typical and atypical samples matched for age/ability is compared at a single point in time (Jarrold \& Brock, 2004). Karmiloff-Smith suggests instead that is crucial to test wide age samples to understand how developmental trajectories of specific functions differ in atypical populations.

The dangers of conceptualising impairments as stable are well illustrated by research mapping developmental trajectories. For instance, Annaz et al (2010) studied biological motion recognition using developmental trajectories, rather than using traditional methodologies of comparing matched samples at a single point in time. They found that children with autism do not differ from typically developing children at 5 years of age in biological motion recognition but they do at 10 years of age. This may explain, at least partly, the large number of studies in autism that provide contradictory findings. A study using traditional methodologies investigating autistic children aged 10 would have concluded that autism is characterised by problems recognising biological motion while a study testing children with autism aged 5 would have concluded that the perception of biological motion is spared in autism. It is clear therefore that to avoid both theoretical and methodological misrepresentation of the nature of developmental disorders, we need to use developmental approaches to their study.

\section{Development of cognitive and behavioural impairments in autism}

Despite the very strong case put forward by Karmiloff-Smith and her colleagues for the importance of understanding how symptoms develop overt time, little is known regarding the developmental trajectory of cognitive and behavioural impairments in autism. In terms of cognitive impairments, to date only three longitudinal studies have been conducted on the development of executive function in autism and these, unfortunately, have found 
contradictory findings, with one study showing improvements over time (Pellicano, 2010) and two others showing increased difficulties over time (Ozonoff \& McEvoy, 1994; Griffith, Pennington, Wehner \& Rogers, 1999). In terms of the development of weak central coherence, only one study to date has examined local processing ability in autism over time (Pellicano, 2010), finding that local processing ability remains fairly stable in autism while it increases with age in typically developing children.

These results seem to support the findings regarding the development of sensory impairments in autism which show that these are already present in the first two years of life (Dahlgren \& Gillberg, 1989; Baranek, 1999) and across the life-span (Billstedt, Gillberg \& Gillberg, 2007; Ben-Sasson et al, 2009). The only study to date that has examined developmental change in sensory impairments show, as Pellicano's (2010) examination of weak central coherence, that sensory over-sensitivity remains stable across time (Green, BenSasson, Soto \& Carter, 2012). In contrast, not all repetitive behaviours seem to be present in autism from an early age. Repetitive behaviours can be classified into two categories: Repetitive Sensory-Motor Behaviours (RSMBs) and Insistence of Sameness (IS) (Szatmari et al, 2006; Leekam et al, 2007). While RSMBs are present in the first 24 months and remain stable (Richler, Huerta, Bishop \& Lord, 2010; Rogers, 2009; Ozonoff et al, 2008; Moore \& Goodson, 2003), IS behaviours tend to emerge around age four and increase over time (Richler et al, 2010; Ventola et al, 2006; Moore \& Goodson, 2003). Studying developmental trajectories therefore is crucial in this context. The distinct developmental trajectories may be due to either RSMBs and IS having different origins or alternatively they may have the same origin initially but in development they may follow different trajectories.

Is mapping developmental trajectories sufficient? 
Karmiloff-Smith and her colleagues provide evidence of modularisation processes emerging in development as well as demonstrating that modularisation processes differ in developmental disorders. However, even if developmental trajectories were mapped for autistics symptoms, it would still be difficult to ascertain the underlying nature of these impairments. This is so because, as valuable as developmental trajectories are in determining when cognitive and behavioural symptoms develop, they do not explain why they develop. Annaz et al's (2010) study for example shows that children with autism differ from typically developing children at age 10 but not at age 5 but it does not explain why their developmental trajectories diverge over time. Although there is now abundant evidence of increased specialisation of the brain and cognitive abilities over the life span (e.g., de Haan \& Nelson, 1999), little is known about which factors contribute to this increased specialisation. Karmiloff-Smith (1992) proposes that, initially, infants have primitive, implicit and nonsymbolic representations of the world which become more complex, and symbolic, through interaction with the environment, a process she calls Representational Redescription. Yet, the factors in the environment that give rise to these changes are not specified in these studies nor in the initial formulation of the theory.

One way of determining these factors is by examining developmental relationships between behavioural symptoms. According to Karmiloff-Smith (2009a) innate deficits have a cascading effect on the development of other cognitive functions. For instance, she argues that the difficulties in visual processing in Williams syndrome, and in particular saccadic planning (Brown et al, 2003) lead to difficulties in following parental pointing (Laing et al, 2002) which results in delayed vocabulary acquisition (Annaz, Karmiloff-Smith \& Thomas, 2008). Yet most research using developmental trajectories fails to examine developmental interactions between areas of ability/impairments; instead these relations are inferred from results from different studies. 
Unfortunately, only two studies have explored developmental relationships between impairments in autism. One examined the relationship between EF, WCC and ToM (Pellicano, 2010) and the other focused on behavioural symptoms (Pellicano, 2012). Both studies found a relationship between impairments, however, the direction of this relationship is unclear as the first study found 'non-social' abilities influence later ToM difficulties and the second study showed a relationship in the opposite direction. Regardless of the explanation for the contradictory findings, these studies provide support for the presence of developmental inter-relationships between social impairments and the 'non-social' symptoms characteristic of autism. These results are not surprising; as it was argued in the introduction that social factors have been shown to be crucial in cognitive development (e.g. Hobson, 2002; Lewis \& Carpendale, 2009). Nevertheless cognitive approaches to psychology tend to ignore the social context. Although it is acknowledged that social interactions may play a role in development, the methodologies and theoretical approaches applied to the study of cognitive development tend to focus on the child rather than on the relation between the child and the social environment. However, there is extensive evidence that social factors influence cognitive development.

\section{The influence of the social environment on modularisation processes}

'I shall be arguing that [...] the tools of thought are constructed on the bases of an infant's emotional engagement with other people. To put it bluntly, if an infant were not involved with other people, then she would not come to think' (Hobson, 2002, p. xiv)

While cognitive developmental theories focus on the infant, alternative approaches in developmental psychology such as those of Vygotsky (1978), Luria (1973), Hobson (2002) or Reddy (2009), to name just a few, view social engagement as central to the origin of 
symbolic thinking and cognitive development. The seminal work of Vygotsky emphasised the socio-cultural context as the medium, not just a contributing factor, to cognitive development. The world that infants first encounter is a social world (Vygotsky, 1998). Hence the environment that triggers the development of genetic predispositions suggested by neuroconstructivist approaches such as Karmiloff-Smiths' is, primarily, a social one.

This social environment influences children's development in three ways. First, it is through emotional engagement/intersubjectivity that infants develop symbolic thinking. In particular, Hobson $(1993 ; 2002)$ argues that by engaging with others the infant becomes able to adopt other people's attitudes to the world and it is the availability to their perspectives that gives rise to symbolic thinking. Second, cultural norms and practices determine what children learn about their environment as even the 'physical' world carries social meaning: "When I speak of one object or another, this means that I not only see the physical properties of the object, but I also generalize the object according to its social purpose" (Vygotsky 1998, p. 277). And finally, the social environment adapts to the child's developmental needs in a reciprocal, dialogical way. Not only does the adult social world influence children's development but children elicit responsivity in parents so, for instance, parents adapt their speech (i.e., 'motherese') to enhance language development (Stern, Spekier \& MacKain, 1982) and use various scaffolding techniques to facilitate the learning of new skills in their children (Wood, Bruner \& Ross, 1976).

The role of intersubjectivity in the development of symbolic thinking

Hobson's $(1993 ; 2002)$ proposal that emotional engagement/intersubjectivity is the key to the development of symbolic thinking has had a large impact on both typical development research and research in autism. As mentioned earlier, Hobson $(1993 ; 2002)$ argues that it is through engaging with others that infants can repeatedly move from having 
an egocentric stance of the world to adopting other people's attitudes to the world. And it is this repeated shifting in perspectives that lies at the heart of the emergence of symbolic play, joint attention, imitation, self-awareness, and, ultimately, theory of mind ability; all abilities which have been shown to be impaired in autism. As the quotation heading this section states, symbolic thinking would not be possible without prior availability to others' attitudes to the world through emotional engagement. This explanation of the development of symbolic thinking stands in stark contrast to the cognitive view that other people's attitudes to the world are not available to the child until around age four when children fully develop ToM (Wimmer \& Perner, 1983). According to the cognitive view, what enables infants to develop joint attention, symbolic play, imitation and self-awareness is the ability to meta-represent, an ability that has been proposed to be impaired in autism (Leslie, 1987).

A full evaluation of these two perspectives is beyond the scope of this article; however, the research by Hobson and others illustrates how examining the role of intersubjectivity in autism can shed light on the nature of the difficulties children with autism encounter. This approach, unlike cognitive research, investigates how children with autism engage with others rather than isolating the child from his/her social context. Overall, these studies not only demonstrate that difficulties in emotional engagement are pervasive in autism, but that impairments in symbolic play, imitation and self-awareness are not the result of meta-representational difficulties but of problems in emotional engagement.

For instance, Hobson et al (2009) have demonstrated that children with autism are actually able to follow the mechanics of symbolic play, but they tend to have less fun and find the pretending uncomfortable. That is, they do not have difficulty with metarepresentation ability per se, but with sharing the experience of play with a play partner. They are also able to imitate a behaviour performed by a social partner, but not the style in which the behaviour is performed. This again shows that the mechanics of imitation are intact, but it 
is the ability to share experiences with others that is problematic (Hobson \& Hobson, 2008). In a similar vein, children with autism express as much laughter as children without autism but they tend not to join in other people's fun or share their mirth (Reddy, Williams \& Vaughan, 2002). And the problems of engagement are not restricted to engaging with others but also with the self. Reddy, Williams, Costantini and Lang (2010) have found that children with autism, independently of whether they pass the mirror self recognition test or not, show less affect towards their reflection than typically developing infants or children with Down syndrome.

Emotional engagement therefore underlies some of the common features of autism. The problem with these studies, however, is that they do not directly investigate the developmental relationship between intersubjective engagement and the development of symbolic functioning, imitation and self-awareness, in autism or even typical development, but this relationship is inferred from findings from different studies. This research therefore needs to incorporate developmental methodologies (i.e., longitudinal studies or developmental trajectories) to map the precise developmental relationship between intersubjective engagement and cognitive development. This research has two additional limitations: one, it focuses on a very specific aspect of the social context (i.e., intersubjective engagement) in which children develop and two, it focuses primarily on the child's behaviour. As mentioned earlier, however, infants relate to their social environment in a reciprocal dialogical way and so it is important to examine the impact that autism has on others' behaviours.

\section{A dialogical perspective to autism}

If autism is the result of 'disturbances of affective contact' (Kanner, 1943, p. 250) then the dialogical relationship of infants with autism and their social environment must 
necessarily be atypical. There were a handful of studies investigating mother-child interactions in autism in the 1980s (i.e., Kasari, Sigman, Mundy \& Yirmiya, 1988; Sigman, Mundy, Sherman \& Ungerer, 1986); however, due to the dominance of the cognitive approach during the 1980s and 1990s, only recently has research started to focus again on relational aspects of autism (Doussard-Roosevelt, Joe, Bazhenova \& Porges, 2003; Adamson, McArthur, Markov, Dunbar \& Bakeman, 2001). Overall these studies clearly show that the maternal behaviour towards children with autism adapts to the difficulties they experience. Mothers of children with autism for instance tend to use physical means to communicate rather than using verbalisations or pointing (Doussard-Roosevelt et al, 2003; Kasari et al, 1988) probably to compensate for the difficulties children with autism have with joint attention (Adamson et al, 2001). Also, mothers of children with autism refer more often to things outside of the child's focus of attention than mothers of typically developing children (Watson, 1998) as a way of overcoming the difficulties in shifting attention which children with autism encounter (Courchesne et al, 1994). More worryingly, there is evidence that reduced vocalizations in the first six months of life of infants later diagnosed with autism results in shorter periods of engagement and a reduction of affectionate touch by the mothers (Apicella et al, 2013).

Nevertheless, although it is helpful to document how maternal behaviour adapts to the needs of a child with autism, it is also necessary to investigate how these adaptations may impact on the child's later cognitive development. As discussed earlier, the brain undergoes a process of modularisation via the interaction of the child and their environment (KarmiloffSmith, 1992; 2009). If this environment is primarily social as suggested by Vygotsky (1978), then it is crucial to understand not only how the genetic impairments in autism elicit specific maternal behaviours, but also how these elicited maternal behaviours impact on the later development of the child. That is, not only do we need to take a dialogical approach to autism 
to describe the relationship between the child and their social environment but we also need to describe how this relationship develops.

\section{The role of cultural practices and norms}

The third aspect in which the social environment influences modularisation is by processes of enculturation. Despite the undeniable influence that socio-cultural factors have on cognitive development, the large majority of research on autism still neglects this influence with rather serious consequences. Let's take Vygotsky's (1998) idea that physical objects carry social meaning as an example of how the conceptualisation of the environment as primarily social may affect our understanding of autism. If objects carry social meaning, and their function is socially determined, then children with autism should have difficulty learning to use objects. Object use in autism, however, has rarely been studied partly because they are considered to be 'non-social' in nature and partly because Kanner (1943) stated that children's relations with objects are unaffected in autism. When researchers have investigated this skill in autism, however, the results have been surprising. Parents report difficulties in learning how to use everyday objects (Williams, Kendall-Scott \& Costall, 2005) and direct observations also indicate problems in object use during functional play (Williams, Costall \& Reddy, 2001). Loveland (1991) argues that these difficulties are specifically related to the learning of social affordances of objects (e.g. picking up a teapot by the handle) rather than their physical affordances (e.g., picking up a teapot by the spout). These findings raise the question of whether cultural practices and norms influence the development of autism. Existing research from typical development and cross-cultural studies may provide some indirect indication on the role cultural practices play on the development of specific autistic symptoms. 
The role of cultural practices in the development of executive function: The presence of Restricted and Repetitive Behaviours (RRBs) in autism have been explained as a result of impaired EF (Ozonoff, Pennington \& Rogers, 1991; Russell, 1997; Turner, 1997) resulting from abnormalities in frontal lobe structure and functioning (Zilbovicius et al, 1995; Chugani et al, 1997; Ozonoff, et al, 1991) which are implicitly believed to be genetic (Ronald, Happé \& Plomin, 2005). There is wide evidence, however, that cultural practices influence the development of EF abilities. Studies have demonstrated that the development of executive functions is influenced by socioeconomic status (e.g., Noble, McCadliss \& Farah, 2007; LiGrining, 2007), type of schooling (Gerdstad, Hong \& Diamond, 1994), parental scaffolding (Bibok, Carpendale \& Müller, 2009), inconsistent parenting (e.g., Hughes \& Ensor, 2009), the use of narratives (McGuigan \& Núñez, 2006) and culture differences have been shown in its development (Oh \& Lewis, 2008). Cultural differences have been explained in terms of parental and school practices (French \& Song, 1998; Kwon, 2002; Chao \& Tseng, 2002). Hence, EF difficulties in autism, and by extension RRBs, may well be, at least partially, explained by the social difficulties present in autism.

The role of culture in perceptual development: Autism is characterised by a local perceptual bias (Frith, 1989; 2003). Like executive function theory, a hidden assumption of WCC theory is that social factors do not influence the development of perceptual biases but that the basis of the impairments is organic. In particular, Happé and Frith (2006) link WCC to evidence showing abnormalities in the dorsal stream (Spencer et al, 2000) and reduced connectivity in the brain (Brock, Brown, Boucher \& Rippon, 2002). As mentioned in the introduction of this article when illustrating the danger of not taking into account the role of social factors on development, there is extensive evidence that perceptual biases are strongly influenced by culture (deFockert et al, 2007; Davidoff, Fonteneau \& Fagot, 2008; Simons \& Levin, 1997; Chua et al, 2005). And this difference influences brain development (Gron, Schul, 
Bretschneider, Wunderlich \& Riepe, 2003). Unlike EF, however, there is no research looking at precisely which cultural practices influence the development of perceptual bias. In certain Eastern cultures parental practices place more importance on group/shared activities than on individual activities. Such practices may encourage attentional/perceptual biases towards relationships rather than individual items (Martini, 1996), but this possibility needs to be explored further.

Cultural differences in the expression of autistic symptoms: Given the overwhelming evidence that socio-cultural factors influence the development of both executive functioning and perceptual processing biases in typical populations, it would be reasonable to predict cultural variations in the expression of autistic symptoms. Due to the widespread belief that autistic symptoms are largely genetic (Weiss et al, 2009; Glessner et al, 2009) and therefore little influenced by social factors, it has been only recently that researchers have started investigating the possibility that there may be cultural differences in the actual expression of symptoms. Such variation has been found in relation to social skills (UK vs. USA, Sipes, Ferniss, Matson \& Hattier, 2012), challenging behaviours (US vs. UK, Chung et al, 2012), and co-morbid symptoms (Zachor et al, 2011).

In a comprehensive study, Matson et al (2011) compared non-verbal communication, verbal communication, social relationships and insistence of sameness/restricted interests in four cultures: Israel, South Korea, United Kingdom and the United States. They found significant differences for all measures except social relationships which suggests that social interaction difficulties are a universal feature of autism. More relevant to the findings regarding EF, they found higher scores in insistence of sameness/restricted interests in the UK and US than in South Korea and Israel. This pattern of results adds support to the notion that EF development is subject to social influence and fits very well with the findings of 
advanced executive function development in South Korea relatively to the UK (Oh \& Lewis, 2008). Differences were also found in the only item relating to sensory issues (i.e., prefers food of a certain texture or smell), with $85 \%$ of parents reporting this to be a problem in the UK in contrast to $36 \%$ and $42 \%$ in Israel and South Korea respectively.

The evidence from these studies clearly demonstrates that socio-cultural factors influence the development and the presence or absence of 'non-social' impairments in autism and hence that autism needs to be studied not only from a developmental perspective, as Karmiloff-Smith suggests, but taking the social context as a serious contributor to modularisation processes. Future research needs to take these cultural differences seriously and investigate the precise cultural practices that give raise to particular perceptual biases and EF impairments. Identifying which symptoms may not be universal in autism is crucial as they may inform ways to promote $\mathrm{EF}$ and global perceptual biases to minimise these difficulties in later life.

\section{The need to take a socio-neuroconstructivist approach to the study of autism}

The evidence that intersubjective impairments are present in autism already in the first year of life is now overwhelming (Zwaigenbaum, et al 2005, Saint-Georges, 2010, Maestro, Muratori \& Cesari, 2005a). The origins of these impairments and how they impact on cognitive development are, as yet, relatively unknown. So far this paper has argued that the neuro-constructivist approach tends to ignore the influence of social factors in development and, in contrast, intersubjective perspectives tend to study intersubjectivity at a single point in time rather than from a developmental perspective. In other words, this paper has presented these two perspectives as alternative, almost mutually exclusive, explanations. This would have been an accurate portrayal not that long ago. However, in recent years there has been an almost imperceptible shift towards the integration of the two perspectives. On the one hand, 
Karmiloff-Smith has argued convincingly towards the importance of exploring the interplay of genetic and social environmental factors in the development of neurodevelopmental disorders (Karmiloff-Smith et al, 2012) and evidence is emerging of the impact of social factors in typical development. For instance, Karmiloff-Smith and colleagues have shown that much of the individual differences in typical infants' cognitive abilities can be accounted for by differences in dyadic interactions (Karmiloff-Smith et al, 2010) and that social aspects, such as socio-economic status, influence brain functional and structural development (Tomalski et al, 2013). This approach, however, has not yet been directly applied to the study of autism and, more crucially, does not, even in typical development research, focus on the role of intersubjectivity in cognitive development. On the other hand, researchers interested in intersubjectivity have 'taken the lead' by increasingly acknowledging the need to understand both the neurobiological origins of intersubjectivity impairments in autism (Trevarthen, 2000) and how they impact on development (Muratori \& Maestro, 2007). Although various theoretical proposals have been made regarding the causal chain from neurobiology to social development in early infancy and autism (e.g., Porges, 2007; Porges \& Furman, 2011; Trevarthen \& Daniel, 2005) little empirical evidence is available yet to support these proposals. These attempts to merge the two perspectives are encouraging but need to be taken seriously and developed much further. As it has been argued throughout this paper, to understand autism, and typical development for that matter, it is crucial to develop a theoretical model of how intersubjectivity impairments in autism impact on the development of neurological, cognitive and behavioural symptoms. 


\section{References}

Adamson, L. McArthur, D. Markov, Y. Dunbar, B. \& Bakeman, R. (2001). Autism and joint attention: Young's children's responses to maternal bids. Journal of Applied Developmental Psychology, 22(4), 439-453. doi: 10.1016/S0193-3973(01)00089-2.

Annaz, D., Karmiloff-Smith, A. \& Thomas, M. (2008). The importance of tracing developmental trajectories for clinical child neuropsychology. In J. Reed \& J. Warner Rogers (Eds.), Child neuropsychology: Concepts theory and practice (pp. 7-18). Oxford, UK: Wiley-Blackwell. doi: 10.1017/S1355617710001232.

Annaz, D., Remington, A., Milne, E. Coleman, M., Campbell, R., Thomas, M., \& Swettenham, J. (2010). Development of motion processing in children with autism. Developmental Science, 13(6), 826-838. doi: 10.1111/j.1467-7687.2009.00939.x.

Ansari, D., \& Dhital, B. (2006). Age-related changes in the activation of the intraparietal sulcus during nonsymbolic magnitude processing: An event-related functional magnetic resonance imaging study. Journal of Cognitive Neuroscience, 18(11), 1820-1828. doi: 10.1162/jocn.2006.18.11.1820.

Apicella, Chericoni, Cosntanzo, Baldini, Billeci, Cohen \& Muratori, (2013). Reciprocity in interaction: A window on the first year of life in autism. Autism Research and Treatment, Article ID 705895. doi: 10.1155/2013/705895.

Ballantyne, C. (2010). The visuo-spatial hierarchical processing trajectories of typical and atypical development : A neuroconstructivist approach. Unpublished $\mathrm{PhD}$ dissertation. Caledonian University.

Baranek (1999). Autism during infancy: A retrospective video analysis of sensory-motor and social behaviours at 9- 12 months of age. Journal of Autism and Developmental Disorders, 29(3), 213-224. doi: 10.1023/A:1023080005650. 
Ben-Sasson, A., Hen, L., Fluss, R., Cermak, S., Engel-Yeger, B. \& Gal, E. (2009). A metaanalysis of sensory modulation symptoms in individuals with autism spectrum disorders. Journal of Autism and Developmental Disorders. 39(1), 1-11. doi: 10.1007/s10803-0080593-3.

Bibok, M., Jeremy, I. \& Carpendale. Parental scaffolding and the development of executive function (2009). In C. Lewis \& J.M. Carpendale (eds.), Social interaction and the development of executive function. New Directions in Child and Adolescents Development, 123, 17-34. doi: 10.1002/cd.233.

Billstedt, E., Gillberg, C. \& Gillberg, C. (2007). Autism in adults: symptom patterns and early childhood predictors. Use of the DISCO in a community sample followed from childhood. Journal of Child Psychology and Psychiatry, 48(11), 1102-1110. doi: 10.1111/j.1469-7610.2007.01774.x.

Brock, J., Brown, C., Boucher, J. \& Rippon, G. (2002). The temporal biding hypothesis of autism. Development and Psychopathology, 14, 209-224. doi: 10.1017/S0954579402002018.

Brown, J., Johnson, M., Paterson, S. Gilmore, R Gsödl, M., Longhi, E. et al.(2003).Spatial representation and attention in toddlers with Williams syndrome and Down syndrome. Neuropsychologia, 41, 1037-1046. doi: 10.1016/S0028-3932(02)00299-3.

Chao, R., \& Tseng, V. (2002). Parenting of Asians. In M. H. Bornstein (Series Ed.), Handbook of parenting: Vol. 4. Social conditions and applied parenting (pp. 59-93). Mahwah, NJ: Lawrence Erlbaum.

Chua,H., Boland, J. \& Nisbett, R. (2005).Cultural variation in eye movements during scene perception. Proceedings of the National Academy of Sciences, 102(35), 12629-12633. doi: 10.1073/pnas.0506162102. 
Chugani, D. C., Muzik, O., Rothermel, R., Behen, M., Chakraborty, P., Mangner, T., Da Silva, E. A. and Chugani, H. T. (1997), Altered serotonin synthesis in the dentatothalamocortical pathway in autistic boys. Annals of Neurology, 42, 666-669. doi: 10.1002/ana.410420420.

Chung, K., Jung, W. Jae-won Yang, J., Ben-Itzchak, E., Zachor, D., Furniss, F., Heyes, K., Matson, J., Kozlowski, A., \& Barker, A. (2012). Cross cultural differences in challenging behaviors of children with autism spectrum disorders: An international examination between Israel, South Korea, the United Kingdom, and the United States of America.

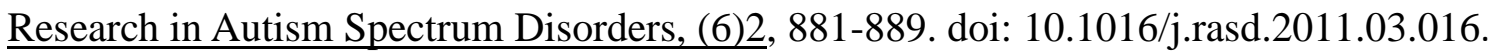

Cornish, K., Scerif, G. \& Karmiloff-Smith, A. (2007). Tracing syndrome-specific trajectories of attention across the lifespan. Cortex, 43, 672-685. doi: 10.1016/S00109452(08)70497-0.

Courchesne, E., Townsend, J., Akshoomoff, N. A., Saitoh, O., Yeung-Courchesne, R. Lincoln, A.,...\& Lau, L.(1994). Impairment in shifting attention in autistic and cerebellar patients. Behavioral Neuroscience, Vol 108(5), 848-865. doi: 10.1037/07357044.108.5.848.

Dahlgren, S. \& Gillberg, C. (1989). Symptoms in the first two years of life. A preliminary population study of infantile autism. European Archives of Psychiatry and Neurology Sciences, 283, 169-174. doi: 10.1007/BF00451006.

Davidoff, J., Fonteneau, E., Fagot, J. (2008). Local and global processing: Observations from a remote culture. Cognition, 108(3), 702-7097. doi: 10.1016/j.cognition.2008.06.004. de Fockert, J., Davidoff, J., Fagot, J., Parron, C. \& Goldstein, J. (2007). More accurate size contrast judgments in the Ebbinghaus Illusion by a remote culture. Journal of Experimental Psychology: Human Perception and Performance, 33(3), 738-742. doi: 10.1037/0096-1523.33.3.738. 
de Haan, M. \& Nelson, C. (1999). Brain activity differentiates face and object processing by 6 months infants. Developmental Psychology, 34, 1114-1121. doi: 10.1037/00121649.35.4.1113.

Doussard-Roosevelt, J., Joe, C., Bazhenova, O. \& Porges, S. (2003). Mother-child interaction in non-autistic children: Characteristics of maternal approach behaviours and child social responses. Development \& Psychopathology, 15(2), 277-295. doi: 10.1017/S0954579403000154.

Fodor, J. (1983). The modularity of the mind. Cambridge, MA: MIT press.

French \& Song (1998). Developmentally appropriate teacher-directed approaches: images from Korean kindergartens Journal of Curriculum Studies, 30(4), 409-430. doi: 10.1080/002202798183558.

Frith (1989). Autism: Explaining the enigma. Oxford: Blackwell Publishers.

Frith (2003). Autism: Explaining the enigma (2nd ed). Oxford: Blackwell Publishers.

Glessner, J., Wang, K., Cai, G., Kortvaska, O., Kim, C., Wood, S.,...\& Hakonarson, H. (2009). Autism genome-wide copy number variation reveals ubiquitin and neuronal genes. Nature, 459, 569-573. doi: 10.1038/nature07953.

Gerdsatd, C., Hong, Y. J. \& Diamond, A. (1994). The relationship between cognition and action-Performance of children $3 \quad 1 / 2-7$ years old on a stroop-like day-night test. Cognition, 53, 129-153. doi: 10.1016/0010-0277(94)90068-X.

Green, S., Ben-Sasson, A., Soto, T. \& Carter, A. (2012). Anxiety and sensory overresponsivity in toddlers with autism spectrum disorders: Bidirectional effects across time. Journal of Autism and Developmental Disorders, 42(6), 1112-1119. doi: 10.1007/s10803-011-1361-3. 
Griffith, E., Pennington, B., Whener, E. \& Rogers,S. (1999). Executive functions in young children with autism. Child Development, 70 (4), 817-832. doi: 10.1111/14678624.00059.

Gron, G., Schul, D., Bretschneider, V., Wunderlich, A. \& Riepe, M. (2003). Alike performance during nonverbal episodic learning from diversely imprinted neural networks. European Journal of Neuroscience, 18(11), 3112-3120. doi: 10.1111/j.14609568.2003.03060.x.

Happé, F. \& Frith, U. (2006). The weak coherence account: Detailed-focused cognitive style in autism spectrum disorders. Journal of Autism and Developmental Disorders, 36, 5-25. doi: 10.1007/s10803-005-0039-0.

Hobson, P. \& Hobson J. (2008). Dissociable aspects of imitation: a study in autism. Journal of Experimental Child Psychology, 101(3), 170-185. doi: 10.1016/j.jecp.2008.04.007.

Hobson, P. (1993). Autism and the development of mind. Hove: Erlbaum.

Hobson, P. (2002). The cradle of thought. London: Macmillan.

Hobson, P., Lee A. \& Hobson, J. (2009). Qualities of symbolic play among children with autism: a social-developmental perspective. Journal of Autism and Developmental Disorders, 39(1), 12-22. doi: 10.1007/s10803-008-0589-z.

Hughes, C. \& Ensor, R. (2009). How do families help or hinder the emergence of early executive function? In C. Lewis \& J.M. Carpendale (eds.), Social interaction and the development of executive function. New Directions in Child and Adolescents Development, 123, 35-50. doi: 10.1002/cd.234.

Jarrold, C. \& Brock (2004). To match or not to match: Methodological issues in autismrelated research. Journal of Autism and Developmental Disorders, 34(1), 81.86. doi: 10.1023/B:JADD.0000018078.82542.ab. 
Johnson, M. \& de Haan, M. (2001).Developing cortical specialization for visual-cognitive function: The case of face recognition. In J.L. McClellan and R.S. Siegler (Eds.), Mechanisms of cognitive development: Behavioural and neural perspectives (pp. 253270). Mahwah: NJ: Erlbaum.

Kanner, L. (1943). Autistic disturbances of affective contact. Nervous Child, 2, 217-250.

Karmiloff-Smith, A. (1992) Beyond Modularity: A Developmental Perspective on Cognitive Science. Cambridge, Mass.: MIT Press/Bradford Books.

Karmiloff-Smith, A. (1998). Developmental itself is the key to understanding developmental disorders. Trends in Cognitive Sciences, 2(10), 389-398. doi: 10.1016/S13646613(98)01230-3.

Karmiloff-Smith, A. (2009a). Nativism versus neuroconstructivism: Rethinking the study of developmental disorders. Developmental Psychology, 45(1), 56-63. doi: 10.1037/a0014506.

Karmiloff-Smith, A. (2009b). Preaching to the converted? From constructivism to neuroconstructivism. Child Development Perspectives, 3(2), 99-102. doi: 10.1111/j.1750-8606.2009.00086.x.

Karmiloff-Smith, A. (2010). Neuroimaging of the developing brain: Taking "developing" seriously. Human Brain Mapping, 31, 934-941. doi: 10.1002/hbm.21074.

Karmiloff-Smith, A., Thomas, M. S. C., Annaz, D., Humphreys, K., Ewing, S., Brace, N., van Duuren, M., Pike, G., Grice, S., \& Campbell, R. (2004). Exploring the Williams Syndrome Face Processing Debate: The importance of building developmental trajectories. Journal of Child Psychology and Psychiatry, 45(7), 1258-1274. doi: 10.1111/j.1469-7610.2004.00322.x.

Karmiloff-Smith, A., Aschersleben, G., de Schonen, S., Elsabbagh, M., Hohenberger, A. \& Serres, J. (2010). Constraints on the timing of infant cognitive change: Domain-specific 
or domain-general? European Journal of Developmental Science, 4(1), 31-45. doi: 10.3233/DEV-2010-4103.

Karmiloff-Smith, A., D’Souza, D., Dekker, T., Van Herwegen, J., Xu, F., Rodic, M. \& Ansari, D. (2012). Genetic and environmental vulnerabilities in children with neurodevelopmental disorders. Proceedings of the National Academy of Sciences, 209(suppl2), 17261-17265. doi: 10.1073/pnas.1121087109/-/DCSupplemental.

Kasari, C., Sigman, M., Mundy, P. \& Yirmiya, N. (1988). Caregiver interaction with autistic children. Journal of Abnormal Child Psychology, 16(1), 45-56. doi: 10.1007/BF00910499.

Kwon, H., Reiss, A. \& Menon, V. (2002). Neural basis of protracted developmental changes in visuo-spatial working memory. Proceedings of the National Academy of Sciences, 99, 13336-13341. doi: 10.1073/pnas.162486399.

Kwon, Y-I. (2002). Western influences in Korean preschool education. International Education Journal, 3, 153-164.

Laing, E., Butterworth, G. Ansari, D. Gsödl, M. Longhi, E. Panagiotaki, G. et al. (2002). Atypical development of language and social communication in toddlers with Williams syndrome. Developmental Science, 5, 233-246. doi: 10.1111/1467-7687.00225.

Leekam. S., Tandos, J. McConachie, H. Meins.E. Parkinson, K., Wright, C. et al (2007). Repetitive behaviours in typically developing 2-year-olds. Journal of Child Psychology and Psychiatry, 48(11), 1131-1138. doi: 10.1111/j.1469-7610.2007.01778.x.

Leslie, A. (1987). Pretense and representation: The origins of "theory of mind". Psychological Review, 94(4), 412-426. doi: 10.1037/0033-295X.94.4.412.

Lewis, C. \& Carpendale, J. (2009). Links between social interaction and executive function.

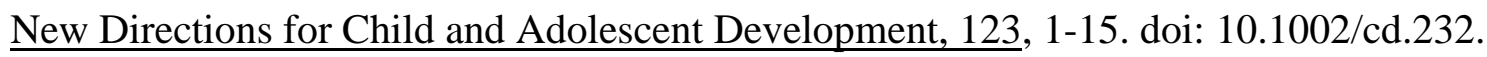


Li-Grining,C.P. (2007) Effortful control among low-Income preschoolers in three cities: stability, change, and individual differences. Developmental Psychology (43), 208-221. doi: 10.1037/0012-1649.43.1.208.

Loveland, K. (1991). Social affordances and interaction II: Autism and the affordances of the human environment. Ecological Psychology, 3(2), 99-119. doi: 10.1207/s15326969eco0302_3.

Luria, A. (1973). The working brain: An introduction to neuropsychology. New York, NY: Basic Books.

Maestro, S. Muratori, F. \& Cesari A. (2005a). Course of autism signs in the firts year of life. Psychopathology, 38, 26-31. doi: 10.1159/000083967.

Martini, M. (1996). "What's new?" at the dinner table: Family dynamics during mealtimes in two cultural groups in Hawaii. Early Development and Parenting, 2-23-34. doi: 10.1002/(SICI)1099-0917(199603)5:1<23::AID-EDP111>3.0.CO;2-D.

Matson, J., Worley, J., Fodstad, J., Chung, K-M., Suh, S., Jhin, H. et al (2011) A multinational study examining cross-cultural differences in reported symptoms of autism spectrum disorders: Israel, South Korea, the United Kingdom and the United States of America. Research in Autism Spectrum Disorders, 5, 1598-1604. doi: 10.1016/j.rasd.2011.03.007.

McGuigan, N. \& Núñez, M. (2006). Executive Functioning by 18-24-month-old children: Effects of Inhibition, working memory demands and narrative in a novel detour-reaching task. Infant and Child Development, 15, 519-542. doi: 10.1002/icd.477.

Moore, V. \& Goodson, S. (2003). How well does early diagnosis of autism stand the test of time? Follow-up study of children assessed for autism at age 2 and development of an early diagnostic service. Autism, 7, 47-63. doi: 10.1177/1362361303007001005. 
Morton, J. \& Johnson, M. (1991). Conspec and conlern: A two-process theory of infant face recognition. Psychological Review, 98, 164-181. doi: 10.1037/0033-295X.98.2.164.

Muratori, F. \& Maestro S. (2007). Autism as a downstream effect of primary difficulties in intersubjectivity interacting with abnormal development of brain connectivity. International Journal of Dialogical Science, 2(1), 93-118.

Noble K., McCandliss, B. \& Farah, M. (2007). Socioeconomic gradients predict individual differences in neurocognitive abilities. Developmental Science, 10, 464-480. doi: 10.1111/j.1467-7687.2007.00600.x.

Oh, S. \& Lewis, C. (2008). Korean preschoolers' advanced inhibitory control and its relation to other executive skills and mental state understanding. Child Development, 79, 80-99. doi: 10.1111/j.1467-8624.2007.01112.x.

Ozonoff, A., Pennington, S. \& Rogers, X (1991). Executive functioning deficits in highfunctioning autistic individuals: Relationship to theory of mind. Journal of Child

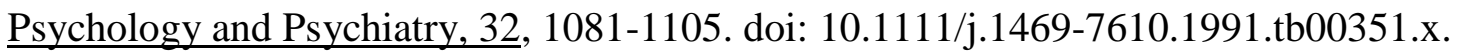

Ozonoff, S. \& McEvoy, R.(1994). A longitudinal study of executive function and theory of mind development in autism. Development and Psychopathology, 6, 415-431. doi: 10.1017/S0954579400006027.

Ozonoff, S., Macari, S., Yong, G. Goldring, S., Thompson, M., \& Rogers, S. (2008). Atypical objects exploration at 12 months of age is associated with autism in a prospective sample. Autism, 12, 457-472. doi: 10.1177/1362361308096402.

Pellicano, E. (2010). The development of core cognitive skills in autism: A 3-year prospective study. Child Development, 81(5), 1400-1416. doi: 10.1111/j.14678624.2010.01481.x.

Pellicano, E. (2012). Do autistic symptoms persist across time? Evidence of a substantial change in symptomatology over a 3-year period in cognitively able children with autism. 
American Journal of Intellectual and Developmental Disabilities, 111(2), 156-166. doi: 10.1352/1944-7558-117.2.156.

Porges, S. (2007). The polyvagal perspective. Biological Psychology, 74(2), 116-43. doi:10.1016/j.biopsycho.2006.06.009.

Porges, S. \& Furman, S. (1011). The early development of the autonomic nervous system provides a neural platform for social behaviour: A polyvagal perspective. Infant and Child Development, 20(1), 106-118. doi: 10.1002/icd.688.

Reddy, V. (2009). How infants know minds. Cambridge, MA: Harvard University Press.

Reddy, V., Williams, E., \& Vaughan, A. (2002). Sharing humour and laughter in autism and Down's Syndrome. British Journal of Psychology, 93, 219-242. doi: $10.1348 / 000712602162553$.

Reddy, V., Williams, E., Costantini, C., \& Lang, B. (2010). Engaging with the self: Mirror behaviour in autism, Down syndrome and typical development. Autism, 14(5), 531-546. doi: $10.1177 / 1362361310370397$.

Richler, J., Huerta, M., Bishop, S. \& Lord, C. (2010). Developmental trajectories of restricted and repetitive behaviors and interests in children with autism spectrum disorders. Development and Psychopathology 22, 55-69. doi: 10.1017/S0954579409990265.

Rogers, S. (2009). What are infant siblings teaching us about autism in infancy? Autism Research, 2, 125-137. doi: 10.1002/aur.81.

Ronald, A., Happé, F. \& Plomin, R. (2005).The genetic relationship between individuals differences in social and nonsocial behaviours characteristics of autism. Developmental Science, 8(5), 444-458. doi: 10.1111/j.1467-7687.2005.00433.x.

Russell, J. (1997). Autism as an executive disorder. Oxford, NY: Oxford University Press.

Saint-Georges, C., Cassel, R., Cohen, D., Chetouani, M., Laznik, M-C., Maestro, S. \& Muratori, F. (2010). What studies of family home movies can teach us about autistic 
infants: A literature review. Research in Autism Spectrum Disorders, 4(3), 355-366. doi; 10.1016/j.rasd.2009.10.017.

Sigman, M., Mundy, P., Sherman, T. \& Ungerer, J. (1986). Social interaction of autistic mentally retarded and normal children and their caregivers. Journal of Child Psychology and Psychiatry, 27(5), 647-656. doi: 10.1111/j.1469-7610.1986.tb00189.x.

Simion F., Macchi Cassia V., Turati C., Valenza E. (2001). The origins of face perception: Specific vs non-specific mechanisms. Infant and Child Development, 10, 59-65. doi: 10.1002/icd.247.

Simons, D. \& Levin, D. (1997). Change blindness. Trends in Cognitive Sciences, 1, 261267. doi: 10.1016/S1364-6613(97)01080-2.

Sipes, M., Furniss, F., Matson, J. \& Hattier, M. (2012). A Multinational Study Examining the Cross Cultural Differences in Social Skills of Children with Autism Spectrum Disorders: A Comparison between the United Kingdom and the United States of America. Journal of Developmental and Physical Disabilities, 24(2), 145,154. doi: 10.1007/s10882-0119261-1.

Spencer, J., O’Brien, J., Riggs, K., Braddick, O., Atkinson, J. \& Wattam-Bell, J. (2000). Motion processing in autism: Evidence for a dorsal stream deficiency. NeuroReport, 11, 2765-2767. doi: 10.1097/00001756-200008210-00031.

Stern, D., Spekier, S., MacKain, K. (1982). Intonation of contours as signals on maternal speech to pre-linguistic infants. Developmental Psychology, 18(5), 727-735. doi: 10.1037/0012-1649.18.5.727.

Szatmari, P., Georgiades, S., Bryson, S., Zwaigenbaum, L., Roberts, W., Mahoney, W., Goldberg, J. \& Tuff, J. (2006). Investigating the structure of the restricted repetitive behaviours and interests domain of autism. Journal of Child Psychology and Psychiatry, 47(6), 582-590. doi: 10.1111/j.1469-7610.2005.01537.x. 
Tomalski, P., Moore, D., Ribeiro, H., Axelsson, E., Murphy, E., Karmiloff-Smith, A., Johnson, M. \& Kushnereko, E. (2013). Socio-economic status and functional brain development associations in early infancy. To appear in Developmental Science.

Trevarthen, C. (2000). Autism as a neurodevelopmental disorder affecting communication and learning in early childhood: prenatal origins, post-natal course and effective educational support. Prostaglandins, Leukotrienes and Essential Fatty Acids, 63(1/2), 4146. doi: 10.1054/plef.2000.0190.

Trevarthen, C. \& Daniel, S. (2005). Disorganised rhythm and synchrony: Early signs of autism and Rett syndrome. Brain and Development, 27(1). 25-34. doi: 10.1016/j.braindev.2005.03.016.

Turner, M. (1997).Towards an executive dysfunction account of repetitive behaviour in autism. In J. Russell (Eds.), Autism as an executive disorder (pp. 57-100). Oxford University Press: Oxford NY.

Ventola, P., Kleinham, J. Pandey, P. Bartonm M., Allen, S., Green et al (2006). Agreement among four diagnostic instruments for autistic spectrum disorders in toddlers. Autism and Developmental Disorders, 36, 839-847. doi: 10.1007/s10803-006-0128-8.

Volkmar, F. R., Paul, R., Klin, A., \& Cohen, D. J. (Eds.). (2005). Handbook of Autism and $\underline{\text { Pervasive Developmental Disorders, Diagnosis, Development, Neurobiology, and }}$ Behavior (Vol. 1). Wiley.

Vygotsky, L. (1978). Mind and society: The development of higher mental processes. Cambridge, MA: Harvard University.

Vygotsky, L. S. (1998). The problem of child (developmental) psychology. In R. W. Rieber (Ed.), The collected works of L. S. Vygotsky, (Volume 5), Child Psychology (pp. 187333). [trans. M. J. Hall.] New York: Plenum Press. 
Watson, L. (1998). Following the child's lead: Mother's interactions with children with autism. Journal of Autism and Developmental Disorders, 28(1), 51-59.doi: 10.1023/A:1026063003289.

Weiss, L., Arkin, D. \& The Gene Discovery Project of Johns Hopkins \& the Autism Consortium (2009). A genome-wide linkage and association scan reveals novel loci for autism, Nature, 461, 802-808. doi: 10.1038/nature08490.

Williams, E., Kendall-Scott, L., \& Costall, A. (2005). Parents' experiences of introducing everyday object use to their children with autism. Autism, 9, 521-540. doi: $10.1177 / 1362361305057869$.

Williams, E., Reddy, V. \& Costall, A. (2001). Taking a closer look at functional play in children with autism. Journal of Autism and Developmental Disorders, 31(1), 67-77. doi: 10.1023/A:1005665714197.

Wimmer, H. \& Perner, J. (1983). Beliefs about beliefs: Representation and constraining function of wrong beliefs in young children's understanding of deception. Cognition $\underline{13(1)}$, 103-128. doi: 10.1016/0010-0277(83)90004-5.

Wood, D., Bruner, J. \& Ross, G. (1976). The role of tutoring in problem solving. Journal of Child Psychology and Psychiatry, 17(2), 89-100. doi:10.1111/j.1469610.1976.tb00381.x.

Zachor, D., Yang J., Ben-Itzchak, E., Furniss, F., Pegg, E., Matson, J., Horovitz, M., Sipes, M., Chung, K. \& Jung, W. (2011). Cross-cultural differences in comorbid symptoms of children with autism spectrum disorders: An international examination between Israel, South Korea, the United Kingdom and the United States of America. Developmental Neurohabilitation, 14 (4), 215-220. doi: 10.3109/17518423.2011.568468. 
Zatlev, J. \& Sinha, C. (2008) (Eds.) The shared mind: Perspectives on intersubjectivity. Converging evidence in language and communication research. Amsterdam: John Benjamins Publishing.

Zilbovicius, M. et al. (1995). Delayed maturation of the frontal cortex in childhood autism. American Journal of Psychiatry, 152 (2), 248-252.

Zwaigenbaum, L., Bryson, S. Rogers, T., Roberts, W., Brian, J. \& Szatmari, P. (2005). Behavioral manifestations of autism in the first year of life. International Journal of Developmental Neuroscience, 23, (2/3), 143-152. doi: 10.1016/j.ijdevneu.2004.05.0. 